\title{
A ward-round non-technical skills for surgery (WANTSS) taxonomy.
}

SCHUUR, K., MURRAY, K., MARAN, N., FLIN, R., PATERSON-BROWN, S. 


\section{A Ward-round Non-Technical Skills for Surgery (WANTSS) Taxonomy}

Authors: Schuur, Klaasa; Murray, Karaa, Maran, Nikki'; Flin, Rhonac; Paterson-Brown, Simon ${ }^{\text {a }}$

Institution: Royal College of Surgeons Edinburgh ${ }^{a}$, Royal Infirmary of Edinburgh ${ }^{b}$, Robert Gordon University ${ }^{c}$

Address for correspondence: klaas.schuur@gmail.com

Funding: SHINE Project 2014-2015, The Health Foundation

Background: Around half of surgical adverse events occur outside the operating room. However the majority of non-technical skills (NTS) training programs have been developed for the intra-operative environment. Ward rounds are a crucial part of extra-operative care and to date no specific NTS training manual has been developed targeting emergency general surgical ward rounds.

Aim: To develop a NTS taxonomy for emergency general surgical ward rounds that can be used to improve surgical team members' NTS and improve outcomes.

Methods: A literature review of existing NTS taxonomies was conducted, followed by semi-structured interviews and observational data collection, to determine good and poor surgical ward round behaviours. These behaviours were reviewed by a panel of subject matter experts and categorised into a taxonomy, using the Non-Technical Skills for Surgeons (NOTSS) taxonomy framework as a guide.

Results: The Ward-round Non-Technical Skills for Surgery (WANTSS) taxonomy includes examples of good and poor ward round specific behaviours, grouped into elements and categories. The taxonomy can be used as both a training and teaching manual for the surgical team.

Conclusion: Ward rounds are a crucial part of extra-operative surgical care. The WANTSS taxonomy provides surgical teams with a manual to help them improve their ward round NTS.

\section{Introduction}

It has been shown that up to $10-15 \%$ of patients admitted to hospital experience some kind of adverse event (AE) not directly related to their condition ${ }^{1}$. Over half of $A E s$ are attributed to surgical specialties ${ }^{1-10}$ and nearly half of these are deemed to be avoidable. ${ }^{1,2,11}$ The consequences of surgical AEs are often more severe than non-surgical $A E s,{ }^{2}$ resulting in extra interventions and treatments, prolonged admissions, disability, readmissions after discharge and subsequent outpatient visits. $^{2,7,11,12}$ Around half of surgical AEs occur in the operating theatre ${ }^{13}$ and the majority have been shown to result from poor non-technical skills (NTS) as opposed to technical failure. ${ }^{1,2,10-12,14-17}$ This has resulted in considerable effort to identify these NTS, with the resulting development of NTS training manuals and assessment tools for the operating theatre. Examples of these include Anaesthetists' Non-Technical Skills (ANTS), ${ }^{18}$ Non-Technical Skills for Surgeons (NOTSS) ${ }^{19}$ and Scrub Practitioners' List of Intra-operative Non-Technical Skills (SPLINTS). ${ }^{20}$ Many of these now form key parts of clinical training curricula in both the UK and overseas.

Around half of surgical adverse events do not arise in the operating theatre and again many are likely to be related to poor ward management, either in preoperative assessment and/or post-operative care. ${ }^{11,12,14,15,21}$ Ward rounds are one of 
the focal points of good extra-operative care and have a proven clinical benefit, ${ }^{22-27}$ providing the main interface between the surgical team and patients: facilitating patient assessment, exchanges of information and management decisions. Unfortunately the quality of surgical ward rounds varies significantly and poor quality ward rounds have been shown to lead to a greater incidence of preventable complications in the High dependency Unit setting. ${ }^{28}$ Due to their significant impact on extra-operative care and significant dependence on NTS, ward rounds are the logical target to improve overall ward-based care. The Foundation Non-Technical Skills (FONTS ${ }^{29}$ taxonomy was recently developed to help assess the NTS of junior doctors providing acute ward-based care, although this did not specifically address ward rounds nor involve other specialties or grades of clinicians. The Teamwork Skills Assessment for Ward Care (T-SAW-C) ${ }^{30}$ provides an assessment tool for surgical ward rounds, but does not have taxonomy nor an accompanying teaching manual of the relevant NTS. Although it might have been possible to adapt this tool in order to produce a taxonomy of these NTS it was felt more appropriate to identify the key NTS directly from the workplace in order to provide a thorough and valid tool. While there have been guidelines developed to improve post-operative care of surgical patients in the high dependency unit, ${ }^{28}$ there have been none which have focussed directly on the NTS required for surgical ward rounds.

ANTS, NOTSS, SPLINTS and FONTS differ from other NTS assessment tools as they have an accompanying taxonomy which serves as a manual to both senior and trainee clinicians about the relevant NTS. Once practitioners have gained an understanding of the relevant NTS they are well-placed to use the accompanying assessment tools to assess the NTS of both themselves and others. It is the taxonomy aspect of these models that was particularly relevant to this project, since the primary goal was to educate staff about NTS rather than assessing them. All non-technical skill taxonomies need to be developed from within the environment they will be used in and by the personnel involved in that aspect of care in order to provide validity to the results. The NOTSS taxonomy framework, in particular, was thought to be suitable as a blueprint in this project because it is directly related to surgeons and surgical care, however, since it was designed for the intra-operative environment, some adjustments would need to be made for the context of the surgical ward environment, hence this project to identify these skills directly from the ward round ebvirnoment.

In an internal survey in our general surgical unit, junior doctors voiced concerns about the process and the quality of the ward rounds. These ward rounds were often fast-paced, covered a large number of patients with varying conditions, occurred over a short period of time and involved multiple team members. Large amounts of information were being exchanged, often in a non-structured and inconsistent manner, which created the potential for error to occur. Since ward rounds constitute a crucial part of extra-operative care, this study was undertaken as a response to these concerns. The aim of this study was therefore to develop a wardround specific NTS taxonomy for teaching and training purposes. It was decided that the study would focus on emergency general surgical ward rounds in the first instance, rather than elective ward rounds since emergency general surgery patients are at a greater risk of adverse events compared to elective patients. ${ }^{31}$ While this does not necessarily mean that poor NTS are the main cause of these adverse events, the relatively higher complication rates in emergency patients compared to elective 
patients would suggest that improvement in this area would be likely to be easier to detect.

\section{Methods}

The project consisted of a pilot questionnaire, a literature review, semistructured interviews with members of the surgical ward round team as well as patients, observational data collection from ward rounds and the eventual taxonomy development. The core project team comprised a surgeon, anaesthetist and psychologist who were subject matter experts involved in the development of NOTSS, ANTS and SPLINTS, as well as a surgical and psychology research fellow. The project was conducted in a general surgical unit in a large teaching hospital. The project was assessed by the South East Scotland Research Ethics Service and it was determined it would not require ethical review under the terms of Governance Arrangements for Research Ethics Committees (A Harmonised Edition).

\section{Pilot Questionnaire}

The concerns raised by the junior doctors in the general surgical unit prompted a pilot questionnaire to be conducted. The purpose of the questionnaire was to assess whether the concerns openly voiced by several junior doctors were shared by their colleagues. The questionnaire was comprised of questions that focused on general impressions, such as perceived efficiency/inefficiency of ward rounds, as well as specific sources of issues ranging from environmental to behavioural. The questionnaire was created on Survey Monkey and emailed to all the junior doctors involved in general surgical ward rounds $(n=12)$ with an accompanying explanation. The questionnaires were completed anonymously and the response rate was $100 \%$.

\section{$\underline{\text { Literature Review }}$}

A literature review was conducted of existing NTS teaching manuals and assessment tools to identify whether any of these would be applicable to emergency general surgical ward rounds. During the literature review, key tasks and behavioural categories targeted by each individual system were highlighted to allow a comparison between them to be made (see Table 1). The models that were assessed included ANTS, NOTSS, SPLINTS, FONTS, Observational Teamwork Assessment for Surgery (OTAS), ${ }^{32}$ Revised NOTECHS, ${ }^{33}$ W-NOTECHS, ${ }^{34}$ Observational Skill-based Clinical Assessment tool for Resuscitation (OSCAR) ${ }^{35}$ and The Teamwork Skills Assessment for Ward Care (T-SAW-C). ${ }^{30}$ All these studies described different NTS assessment tools that could be used to assess the NTS of practitioners in different environments. OTAS aids the assessment of teamwork amongst all members of the surgical team in the operating theatre. As already discussed, T-SAW-C provides a NTS assessment tool for surgical ward rounds, but does not have an accompanying teaching manual of the relevant NTS. As previously discussed, FONTS provides a taxonomy for ward-based care along with its rating scale, but does not address ward rounds, nor is it specific to surgery.

\section{$\underline{\text { Interviews }}$}


A psychology research fellow developed a semi-structured interview schedule with interviews conducted with consultant surgeons $(n=7)$, surgical trainees $(n=2)$, foundation doctors $(n=9)$, nursing staff $(n=22)$ and patients $(n=17)$. All potential staff participants were initially informed about the study via email, outlining the nature of the project, and that they may be asked to participate through engaging in semistructured interviews with the psychology research fellow. Consultant surgeons were offered an appointment for interview. The recruitment of all other participants occurred via opportunistic methods, based on their involvement in the emergency surgical ward rounds. As the 'trainees' refer to the surgical registrars, who are seconded for two weeks at a time to the emergency surgical team, only two were available during this time period for interview. Furthermore the registrars were only usually present for parts of the ward round as they were more commonly involved in the emergency theatre, which commenced at the same time as the morning emergency ward rounds. Separate interview schedules were developed for consultants, since there were certain questions that were specifically targeted towards the team leader. Responses from all participants were anonymised. The interview schedules for consultants and other participants are available in Appendix 1 and 2 respectively. The purpose of the interviews was three-fold: firstly, to identify what the main issues were in relation to the emergency surgical ward rounds; secondly, to ascertain what NTS contributed to a ward round being either good or poor; and lastly, to elicit from the staff what they felt could be done to improve the ward rounds. The interview responses were written down following which the psychologist used principles of grounded theory to identify unique NTS. This generated a list of NTS, the presence of which were felt to contribute to either a good or poor ward round.

\section{Observations}

After the interviews were completed, a two week period of observational data collection was conducted in which a psychologist and surgical research fellow observed team members during ward rounds. The observations were conducted over ten days with one ward round per day and with an average duration of 2 hours 15 minutes. The period of observation started at the morning handover from the night team to day team and finished with the conclusion of the ward round. The average number of team members observed per ward round was seven. Only interactions with certain patients were observed, based on several exclusion criteria which can be viewed in Appendix 3. During the ward rounds the research team monitored for the presence of behaviours which were deemed to be good or poor, in line with the types of behaviours generated from the semi-structured interviews. The purpose of the observations was to gain further insight into the issues highlighted during interviews and to potentially generate further NTS.

\section{$\underline{\text { Taxonomy Development }}$}

A similar framework to ANTS, NOTSS and SPLINTS was adopted for the development of this taxonomy, comprised of key behavioural categories, which are sub-divided into elements under which individual behavioural markers can be categorised. The elements serve as headings for core themes within each behavioural category whereas the markers are examples of specific behaviours, see Table 2 . This 
hierarchical system is based on the NOTECHS marker system developed for European aviation ${ }^{36}$.

\section{Results}

\section{Pilot Questionnaire}

The questionnaire confirmed that the majority of the junior doctors had concerns about the surgical ward rounds (see Table 3 ). The results were presented to the department and recommendations were discussed. Several of the environmental factors were rectified as a result but it was clear that some of the behavioural factors required more in-depth intervention and were therefore addressed in this study.

\section{Interviews}

The interviews and observations yielded 148 unique NTS that could be used as potential markers. The project team conducted analysis of these behaviours, to determine the most appropriate behavioural categories. The behavioural categories that were considered were situation awareness, decision making, communication, teamwork, leadership, managing stress, and coping with fatigue, as previously described by Flin et al. ${ }^{37}$ The project team members then individually selected categories which they felt were appropriate for the taxonomy and then were asked to justify their category selections to the rest of the team. Several different combinations of categories were considered until a consensus was reached. Eventually the categories were narrowed down to four core categories: leadership, situation awareness, decision-making, communication and teamwork. It was felt that it was more appropriate to group communication and teamwork together as a combined category due to their consistent overlap and interdependence in the context of ward round behaviours. The resulting categories overlapped with those used in NOTSS and it was found that the category definitions for leadership and decision-making would also be applicable for this taxonomy. The definitions for situation awareness and communication and teamwork needed to be adapted to be applicable to the ward round environment.

The next part of the project involved the development of the separate elements. The taxonomies from ANTS, NOTSS and SPLINTS were reviewed and it was agreed that the majority of the elements used in NOTSS would also be appropriate for this taxonomy. However, several elements and their definitions had to be adapted to be applicable to the ward round environment.

Lastly, the project team analysed the 148 unique behaviours generated by the interviews and observations and reduced these to those behaviours which contributed the most to high quality ward round performance. These key behaviours became the behavioural markers and were subsequently grouped under relevant behavioural categories and elements with the purpose of serving as examples of both good and poor ward round behaviours. At this stage it was identified that there were two key roles when it came to ward round behaviour: the team leader and the team member. The team leader was defined as the person who was primarily responsible for directing the ward round. A team member was defined as a person whose primary responsibilities were other than directing the ward round. There were distinct 
behavioural markers that applied primarily to the team leader but not to the team members. Other behavioural markers applied to both the team members and the team leader. Therefore, it was decided to split the taxonomy into two parts: with one part consisting of behavioural markers for the team leader and the other consisting of behavioural markers for team members. This was thought to allow the taxonomy to be used by whoever was planning to lead the ward round (in most cases the Consultant) as compared to those 'following', and would permit transfer from one to other group if required.

The resulting taxonomy was reviewed and adjusted multiple times by the project team before producing the prototype taxonomy. The prototype Ward-round Non-Technical Skills for Surgeons (WANTSS) framework (see Table 4) provides a manual with descriptions and definitions of the different NTS in the surgical ward round context. It provides a clear and segmented framework to teach desirable wardround behaviour. The framework allows for a step-wise teaching approach. Practitioners can be taught the behavioural categories to gain a broad understanding of behaviour in the ward-round context. Once this is achieved the elements provide a means of developing an in-depth understanding of each category.

Part two and three of the taxonomy include the different behavioural markers for the team leader and team members respectively, grouped under the relevant behavioural categories (see Tables 5 and 6). The behavioural markers serve as exemplar behaviours to allow practitioners to understand what types of behaviours can be expected in each element. These markers were selected because they were deemed to contribute significantly to either good or poor ward-round quality. In addition to supplementing the understanding of the taxonomy these behavioural markers were also deemed to be desirable or undesirable behaviours for practitioners to exhibit. Therefore, the desirable behavioural markers in, and of themselves, can also be taught as specific target behaviours.

Poor quality of emergency general surgical ward rounds can be brought about by the exhibition of poor behaviours but also by the absence of good behaviours at times when they are desirable. Therefore, it is important to bear in mind that apathy, even though it may not lead to active poor behaviours, is a poor behaviour in, and of itself.

\section{Discussion}

This study was carried out in a single centre and in one general surgical unit. The influence of the local hospital, departmental and specialty specific cultures, practices and clinical requirements needs to be acknowledged in the development of this taxonomy, as well as the relatively small numbers involved. Nonetheless, the behavioural categories and elements mostly overlapped with NOTSS, which was derived from multi-centre and multi-specialty involvement. As a result it is not surprising that the four categories for the NTS of Situation awareness, Decisionmaking, communication \& Teamwork and Leadership were confirmed in WANTSS.

The behavioural markers that serve as examples of desirable or undesirable behaviours in this taxonomy arose from interviews and observations during this study. The project team appreciate that there are numerous other good and poor behaviours that are not included in the taxonomy and the ones in the taxonomy are therefore just 
examples of a much broader group.

The main difference between this taxonomy and ANTS, NOTSS, SPLINTS and FONTS, is that this taxonomy was not developed with an accompanying rating scale that practitioners can use to rate the NTS of others. The focus in these other taxonomies is on assessing the NTS of an individual. Although a ward round has a team leader, many of the expected actions and desired behaviours can be fulfilled by a variety of team members. As a result, it is difficult to assess the ward round NTS of individual team members since individuals work together as a team, to display all the desired NTS. Assessment of the NTS of the entire team could be considered, but it would be difficult to give accurate feedback since only a small number of individuals may be responsible for the majority of the exhibited behaviours. OTAS and OSCAR assess the NTS of multiple team members in the operating and resuscitation environments respectively, but these assessments are based on role-specific observed behaviours which is not practical in the ward round environment. Assessment of the NTS of the team leader may be possible, since there are ward round-specific behaviours for the team leader. However, sometimes teams may display shared leadership ${ }^{38}$ and other team members may cross over and display some of these 'team leader' behaviours in natural interactions. This would impact negatively on the assessment of the team leader, although the overall assessment of NTS for the team would be positive. Regardless of these factors, the focus of this project was teaching and training the clinical team about ward-round NTS through the means of a taxonomy and it was felt that the development of an associated rating scale was beyond the scope of this study. This tool is now available to all members of our emergency surgical multi-disciplinary team and is included in the induction programme for all new doctors. It is envisaged that it will be referred to and used as a reminder of how to conduct/participate in good ward rounds. As the other ward round tools discussed in this paper do not cover all members of the ward round (senior to junior and multi-professional), they are not directly relevant to emergency surgical ward rounds and as a result we feel that this tool is indeed a novel ward round tool.

Even though this taxonomy was developed for emergency general surgical ward rounds, the majority of the NTS identified can also apply to ward rounds in the elective setting or those in other surgical and medical specialties, and this will be a focus for further studies.

\section{Conclusion}

Surgical ward rounds are a crucial part of surgical care and susceptible to error. This study has identified that NTS play a significant role in emergency general surgical ward round performance. Using established NTS taxonomies, a dedicated ward round NTS taxonomy has been developed to help educate staff about good and poor NTS. Using this taxonomy as a teaching platform can give staff the tools to be able to improve their emergency general surgical ward round behaviours. Further studies will need to be carried out in order to determine its clinical benefit. 
Table 1 - Literature Review

\begin{tabular}{|c|c|c|c|c|c|c|c|c|c|c|c|c|}
\hline \multicolumn{3}{|c|}{ Literature } & \multicolumn{10}{|c|}{ Specified Target Domains } \\
\hline Source & Model & $\begin{array}{l}\text { Target } \\
\text { Environment }\end{array}$ & Leadership & $\begin{array}{l}\text { Team } \\
\text { Work }\end{array}$ & Cooperation & $\begin{array}{l}\text { Resources } \\
\text { Management } \\
\text { and } \\
\text { Coordination }\end{array}$ & Communication & Monitoring & $\begin{array}{l}\text { Decision } \\
\text { Making }\end{array}$ & $\begin{array}{l}\text { Situational } \\
\text { Awareness }\end{array}$ & $\begin{array}{l}\text { Task } \\
\text { Management }\end{array}$ & $\begin{array}{l}\text { Coping } \\
\text { with } \\
\text { Stress }\end{array}$ \\
\hline $\begin{array}{l}\text { Fletcher } \\
\text { et al. }{ }^{18}\end{array}$ & ANTS & $\begin{array}{l}\text { Operating } \\
\text { Theatre }\end{array}$ & & $\checkmark$ & & & & $\checkmark$ & $\checkmark$ & $\checkmark$ & $\checkmark$ & \\
\hline $\begin{array}{l}\text { Hull et al. } \\
30\end{array}$ & T-SAW-C & Surgical Ward & $\checkmark$ & & $\checkmark$ & $\checkmark$ & $\checkmark$ & & $\checkmark$ & $\checkmark$ & & \\
\hline $\begin{array}{l}\text { Hull et al. } \\
32\end{array}$ & OTAS & $\begin{array}{l}\text { Operating } \\
\text { Theatre }\end{array}$ & $\checkmark$ & & $\checkmark$ & $\checkmark$ & $\checkmark$ & $\checkmark$ & & $\checkmark$ & & \\
\hline $\begin{array}{l}\text { Mellanby } \\
\text { et al. }{ }^{29}\end{array}$ & FONTS & Ward (Any) & & $\checkmark$ & & & & & $\checkmark$ & $\checkmark$ & $\checkmark$ & \\
\hline $\begin{array}{l}\text { Mitchell } \\
\text { et al. }{ }^{20}\end{array}$ & SPLINTS & $\begin{array}{l}\text { Operating } \\
\text { Theatre }\end{array}$ & & $\checkmark$ & & & $\checkmark$ & & & $\checkmark$ & $\checkmark$ & \\
\hline $\begin{array}{l}\text { Pucher et } \\
\text { al. }{ }^{33}\end{array}$ & W-NOTECHS & Surgical Ward & $\checkmark$ & & $\checkmark$ & $\checkmark$ & $\checkmark$ & & $\checkmark$ & $\checkmark$ & & $\checkmark$ \\
\hline $\begin{array}{l}\text { Sevdalis } \\
\text { et al. }{ }^{34}\end{array}$ & $\begin{array}{l}\text { Revised } \\
\text { NOTECHS }\end{array}$ & $\begin{array}{l}\text { Operating } \\
\text { Theatre }\end{array}$ & $\checkmark$ & & $\checkmark$ & & $\checkmark$ & $\checkmark$ & $\checkmark$ & $\checkmark$ & & \\
\hline $\begin{array}{l}\text { Walker et } \\
\text { al. }{ }^{35}\end{array}$ & OSCAR & Resuscitation & $\checkmark$ & & $\checkmark$ & $\checkmark$ & $\checkmark$ & $\checkmark$ & $\checkmark$ & $\checkmark$ & & \\
\hline $\begin{array}{l}\text { Yule et al. } \\
19\end{array}$ & NOTSS & $\begin{array}{l}\text { Operating } \\
\text { Theatre }\end{array}$ & $\checkmark$ & $\checkmark$ & & & $\checkmark$ & & $\checkmark$ & $\checkmark$ & & \\
\hline
\end{tabular}


Table 2-Taxonomy framework

\begin{tabular}{|l|l|l|}
\hline Category & Element & Marker \\
\cline { 2 - 3 } & & Marker \\
\cline { 2 - 3 } & Element & Marker \\
\hline & Marker \\
\cline { 2 - 3 } & Element & Marker \\
\cline { 2 - 3 } & & Marker \\
\hline
\end{tabular}


Table 3-Pilot Questionnaire

\begin{tabular}{|l|l|l|l|l|l|}
\hline & Never & Rarely & Sometimes & Often & Always \\
\hline Would you rate the ward rounds as efficient? & $0 \%$ & $40 \%$ & $60 \%$ & $0 \%$ & $0 \%$ \\
\hline $\begin{array}{l}\text { Do you get enough time to document in the notes on the ward } \\
\text { round? }\end{array}$ & $18.18 \%$ & $45.45 \%$ & $36.36 \%$ & $0 \%$ & $0 \%$ \\
\hline $\begin{array}{l}\text { Is a clear plan conveyed to you for each patient on the ward } \\
\text { round? }\end{array}$ & $0 \%$ & $9.09 \%$ & $63.64 \%$ & $27.27 \%$ & $0 \%$ \\
\hline $\begin{array}{l}\text { How frequently are you carrying multiple sets of notes AND } \\
\text { writing in the notes at the same time? }\end{array}$ & $0 \%$ & $0 \%$ & $0 \%$ & $41.67 \%$ & $58.33 \%$ \\
\hline $\begin{array}{l}\text { If there are multiple consultants on a ward round, how } \\
\text { frequently do they split off to different patients and are you the } \\
\text { only person expected to write in the notes for both patients? }\end{array}$ & $8.33 \%$ & $0 \%$ & $66.67 \%$ & $25 \%$ & $0 \%$ \\
\hline $\begin{array}{l}\text { How frequently are you told specific request information for a } \\
\text { scan (e.g. AUS, CT abdo) on the ward round? }\end{array}$ & $0 \%$ & $8.33 \%$ & $83.33 \%$ & $8.33 \%$ & $0 \%$ \\
\hline $\begin{array}{l}\text { If you haven't been told specific request information for a scan, } \\
\text { how frequently does this lead to the scan being discontinued or } \\
\text { delayed? }\end{array}$ & $0 \%$ & $0 \%$ & $75 \%$ & $25 \%$ & $0 \%$ \\
\hline
\end{tabular}


Table 4 - WANTSS Taxonomy Framework*

\begin{tabular}{|c|c|c|}
\hline Category & Elements & Definition \\
\hline \multirow[t]{4}{*}{ Leadership } & & $\begin{array}{l}\text { Leading the team and providing direction, demonstrating high standards of clinical } \\
\text { practice and care, and being considerate about the needs of individual team } \\
\text { members. }\end{array}$ \\
\hline & $\begin{array}{l}\text { Setting and Maintaining } \\
\text { Standards }\end{array}$ & $\begin{array}{l}\text { Supporting safety and quality by adhering to established protocols and principles } \\
\text { of good clinical practice. }\end{array}$ \\
\hline & $\begin{array}{l}\text { Supporting Team and } \\
\text { Others }\end{array}$ & $\begin{array}{l}\text { Providing cognitive and emotional help to team members. Judging different team } \\
\text { members' abilities and tailoring one's style of leadership accordingly. }\end{array}$ \\
\hline & Coping With Pressure & $\begin{array}{l}\text { Retaining a calm demeanour when under pressure and } \\
\text { Emphasising to the team that one is under control of a high-pressure situation. } \\
\text { Being assertive if appropriate without undermining the role of other team } \\
\text { members. } \\
\text { Striving to create an inclusive and constructive ward round environment. } \\
\text { Recognising when team members are under pressure and providing appropriate } \\
\text { support. }\end{array}$ \\
\hline \multirow[t]{4}{*}{$\begin{array}{l}\text { Situation } \\
\text { Awareness }\end{array}$} & & $\begin{array}{l}\text { Developing and maintaining a dynamic awareness of the situation on the ward } \\
\text { based on assembling data from the environment (patient, team, time, charts, } \\
\text { equipment); understanding what they mean and thinking about what may happen } \\
\text { next. }\end{array}$ \\
\hline & Gathering Information & $\begin{array}{l}\text { Seeking information on the ward from the patient history, clinical examination, } \\
\text { charts, notes, the operative findings and other staff. }\end{array}$ \\
\hline & Processing Information & $\begin{array}{l}\text { Updating one's mental picture by interpreting the information gathered and } \\
\text { comparing it with existing knowledge to identify the match or mismatch between } \\
\text { the situation and the expected state. }\end{array}$ \\
\hline & Anticipating Future States & $\begin{array}{l}\text { Predicting what may happen in the near future as a result of possible actions, } \\
\text { interventions or non-intervention. }\end{array}$ \\
\hline \multirow[t]{4}{*}{ Decision Making } & & $\begin{array}{l}\text { Diagnosing the situation and reaching a judgement in order to choose an } \\
\text { appropriate course of action. }\end{array}$ \\
\hline & Considering Option & $\begin{array}{l}\text { Generating alternative possibilities or courses of action to solve a problem. } \\
\text { Assessing the hazards and weighing up the threats and benefits of potential } \\
\text { options. }\end{array}$ \\
\hline & $\begin{array}{l}\text { Selecting and } \\
\text { Communicating Options }\end{array}$ & $\begin{array}{l}\text { Choosing a solution to a problem and letting all relevant personnel know the } \\
\text { chosen option. }\end{array}$ \\
\hline & $\begin{array}{l}\text { Implementeing and } \\
\text { Reviewing Decisions }\end{array}$ & $\begin{array}{l}\text { Keeping the team informed of developments and adapting the management plan } \\
\text { to new information. }\end{array}$ \\
\hline \multirow[t]{4}{*}{$\begin{array}{l}\text { Communication } \\
\text { and Teamwork }\end{array}$} & & $\begin{array}{l}\text { All team members provide clear and relevant input on the ward round in order to } \\
\text { ensure that all ideas and concerns are shared, in order to create a shared picture } \\
\text { of the situation. All members of the surgical team feel empowered to contribute to } \\
\text { patient assessment and subsequent management. }\end{array}$ \\
\hline & Team Participation & Ensuring all team members are involved in ward round activities. \\
\hline & Coordination of Activities & $\begin{array}{l}\text { Working together with other team members to carry out cognitive and physical } \\
\text { activities in a simultaneous, collaborative manner. }\end{array}$ \\
\hline & $\begin{array}{l}\text { Establishing a Shared } \\
\text { Understanding }\end{array}$ & $\begin{array}{l}\text { Ensuring that the team not only has necessary and relevant information to carry } \\
\text { out the management plan, but that they understand it and that an acceptable } \\
\text { shared 'big picture' of the case is held by team members. }\end{array}$ \\
\hline
\end{tabular}

*The material developed for the purpose of this study is underlined, the rest is original NOTSS content 


\section{BEHAVIOURS FOR THE TEAM}

\section{GOOD BEHAVIOURS}

\section{POOR BEHAVIOURS}

\section{LEADERSHIP: (Coping with Pressure, and Supporting Team)}

Recognises when other team members are stressed and offers

Does not challenge other members of the team who disregard issues of patient safety

Suppresses concern over a clinical problem

Fails to support other team members

Gives positive feedback to other team members on their performance

\section{SITUATION AWARENESS: (Gathering Information, Processing Information, Projecting Future States)}

Prepares all available documentation and results before the ward round

Clarifies that all patient information is up-to-date and accurate

Recognises severity of clinical condition based on the available information

\section{DECISION MAKING: (Considering Options, Selecting Options, Reviewing Decisions)}

Participates in a balanced discussion of management options with team members

Ensures all team members are in agreement about management plan

Agrees contingency plan depending on new information

\section{COMMUNICATION AND TEAMWORK: (Team Participation, Coordination of Activities, Shared}

\section{Understanding)}

Engages and participates in the ward round

Clarifies the roles and abilities of other team members

Articulates concerns clearly to team members
Does not highlight abnormal results

Fails to consider all available management options

Does not adopt contingency plan when needed
Moves on to the next patient without checking whether all team members are ready

Uses jargon and technical terminology when explaining management plans to patients

Fails to provide transparency about delays or changes in the management plan 
Table 6-WANTSS Behavioural Marker Taxonomy For the Team Leader

\section{BEHAVIOURS FOR THE TEAM LEADER}

GOOD BEHAVIOURS

\section{LEADERSHIP: (Coping with Pressure and Supporting Team)}

Encourages the surgical team to ask questions

Recognizes when team members are stressed and attempts to

support them

Clearly identifies individual roles on the ward round

Ignores concerns from other team members

Responds aggressively and irrationally to errors by team members

Dismisses contributions from team members

\section{SITUATION AWARENESS: (Gathering Information, Processing Information, Projecting Future States)}

Reviews all clinical information

Reaches a differential diagnosis based on all information

Anticipates clinical developments based on differential diagnosis
Ignores input from staff and patient

Fails to check whether the differential diagnosis is supported

by available investigations

Does not formulate management plan based on relevant clinical findings

\section{DECISION MAKING: (Considering Options, Selecting Options, Reviewing Decisions)}

Assesses management options based on most likely diagnosis

Decides on a management plan based on potential risks and benefits

Adopts contingency plan in case of deterioration
Fails to reach a clear management plan

Fails to take into account the risks and benefits of the management plan

Does not reconsider the patient management plan when faced with new information

\section{COMMUNICATION AND TEAMWORKING: (Team Participation, Coordination of Activities, Shared}

\section{Understanding)}

Checks that all team members are in agreement about

management plan

Communicates decision and prioritisation for theatre clearly to relevant team members (including theatre staff)

Informs patients about when they will next be reviewed
Does not provide clear justifications as to why investigations are indicated

Delegates a disproportionate workload to certain team members

Performs clinical assessment without involvement of team members 


\section{Appendix 1}

Emergency Surgical Ward Consultant Interviews

Semi-structured Interviews conducted by KRM

1. What do you hope to achieve from conducting the ward round?

a. What information are you hoping to obtain from the ward round?

2. What does a good ward round look like to you?

a. What actions or behaviours are indicative of a good ward round?

3. What does a bad ward round look like to you?

a. What actions or behaviours are indicative of a bad ward round?

4. How do you find the communication that takes place during the ward round?

a. How do you communicate your thoughts and patient plans to staff during the ward round?

b. Do you find you need to clarify issues or addressed questions raised by staff present on the ward round?

c. How confident to you think staff are in asking questions or asking for clarification during or after the ward round?

d. How is the information from the ward round relayed to the relevant staff afterwards?

i. Are there ever any issues relating to this?

5. How do you find the emergency ward round as a working environment?

a. Is there generally a good working relationship between members of staff?

b. Is there a good understanding of what different job roles exist on the wards and what each of these roles entails?

6. What do you think the patient's experience of the ward round is like?

a. Are there aspects you think that they may be confused about or take issue with?

b. Do you think they are satisfied with the information they receive during the ward round?

i. What sort of information is a typical patient usually provided with?

c. Do you find that patients are comfortable asking questions during the ward round? 
Ward Round Interviews (Between 7/7/14-17/8/14)

Semi-structured Interviews conducted by KRM

\section{Questions:}

What do you think makes a good ward round?

- What actions or behaviours have you seen which you think are helpful during the ward round?

- What behaviours do you think are helpful in relation to how the staff work together?

- What behaviours do you think are helpful in relation to providing effective patient care?

What do you think makes a bad ward round?

- What actions or behaviours have you seen which you think can be problematic during the ward round?

- Are there any things which you can currently think of which you think could be solutions to these problems?

- What actions or behaviours do you think can be problematic in terms of patient care?

What factors affect the ways in which the ward round functions?

- Do the ward rounds function in the same way regardless of which consultant is leading it?

- Do the ward rounds function in the same way regardless of which staff members are present on the team?

- Does the ward round take roughly the same time each time?

- Is the decision making which takes place during the ward round consistent regardless of which staff members are present on the ward round?

How is the communication both during the ward round and afterwards with other relevant staff?

- Is there a good relationship amongst the staff generally?

- Does all the relevant information get relayed to whom it needs to?

- Are there any ways in which you think communication could be improved? 
$\underline{\text { Appendix } 3}$

\section{Observation Patient Selection Criteria}

\begin{tabular}{|l|l|}
\hline \multicolumn{1}{|c|}{ Exclusion Criteria } & \multicolumn{1}{|c|}{ Reason } \\
\hline Elective surgical patients & $\begin{array}{l}\text { Study targeted towards emergency surgical } \\
\text { ward rounds }\end{array}$ \\
\hline Patients with a decreased conscious level & Interaction with patient likely to be altered \\
\hline $\begin{array}{l}\text { Patients with impaired cognitive function } \\
\text { e.g. dementia, intoxicated) }\end{array}$ & Interaction with patient likely to be altered \\
\hline Patient with a poor command of English & Interaction with patient likely to be altered \\
\hline Patients with MRSA & $\begin{array}{l}\text { Patient will be in single rooms. Will require } \\
\text { adherence to infection control protocol to } \\
\text { access patient. Adherence of research team } \\
\text { to infection control protocol might prompt } \\
\text { surgical team to adhere to protocol. } \\
\text { Adherence to infection control protocol by } \\
\text { research team will involve extra time that } \\
\text { would therefore likely influence the } \\
\text { amount of time spent with patients by the } \\
\text { team. }\end{array}$ \\
\hline Consultant Supervisor & $\begin{array}{l}\text { Patient will be in single rooms. Will require } \\
\text { adherence to infection control protocol to } \\
\text { access patient. Adherence of research team } \\
\text { to infection control protocol might prompt } \\
\text { surgical team to adhere to protocol. } \\
\text { Adherence to infection control protocol by } \\
\text { research team will involve extra time that } \\
\text { would therefore likely influence the } \\
\text { amount of time spent with patients by the } \\
\text { team. }\end{array}$ \\
\hline Patients with C.diff & $\begin{array}{l}\text { Consultant supervising project. Therefore } \\
\text { ward rounds will be excluded from data } \\
\text { collection due to primping and biase. }\end{array}$ \\
\hline Questions with regards to consent \\
\hline
\end{tabular}




\section{References}

1. Vincent C, Neale G and Woloshynowych M. (2001). Adverse events in British Hospitals: Preliminary retrospective record review. British Medical Journal, 322, 517-519.

2. Zegers M, De Bruijne MC, De Keizer B, Merten H, Groenewegen PP, Van Der Wal G, and Wagner C. "The Incidence, Root-causes, and Outcomes of Adverse Events in Surgical Units: Implication for Potential Prevention Strategies." Patient Safety in Surgery 5.1 (2011): 13.

3. Baker RG, Norton PG, Flintoft V, Blais R, Brown A, Cox J, Etchells E, Ghali WA, Hébert P, Majumdar SR, O'Beirne M, Palacios-Derflingher L, Reid RJ, and Sheps S. "The Canadian Adverse Events Study: The Incidence of Adverse Events among Hospital Patients in Canada." CMAJ : Canadian Medical Association Journal 170.11 (2004): 1678-1686. PMC.

4. Brennan, T A. "Incidence of Adverse Events and Negligence in Hospitalized Patients: Results of the Harvard Medical Practice Study I." Quality and Safety in Health Care 13.2 (2004): 14551.

5. Davis P, Lay-Yee R, Briant R, Ali W, Scott A, Schug S. Adverse Events in New Zealand public hospitals I: occurrence and impact. N Z Med J 2002, 115(1167):U271.

6. Davis P, Lay-Yee R, Briant R, Ali W, Scott A, Schug S. Adverse Events in New Zealand public hospitals II: preventability and clinical context. N Z Med J 2003, 116(1183):U624.

7. Thomas EJ, Studdert DM, Burstin HR, Orav EJ, Zeena T, Williams EJ, Howard KM, Weiler PC, and Brennan TA. "Incidence and Types of Adverse Events and Negligent Care in Utah and Colorado." Medical Care 38.3 (2000): 261-71.

8. Wilson RM, Runciman WB, Gibberd RW, Harrison BT, Newby L, Hamilton JD. The Quality in Australian Health Care Study. Med J Aust 1995, 163:458-71.

9. Gawande AA, Thomas EJ, Zinner MJ, and Brennan TA. "The Incidence and Nature of Surgical Adverse Events in Colorado and Utah in 1992." Surgery 126.1 (1999): 66-75.

10. Kable AK, Gibberd RW, and Spigelman AD. "Adverse Events in Surgical Patients in Australia." International Journal for Quality in Health Care 14.4 (2002): 269-76.

11. Anderson O, Davis R, Hanna GB, and Vincent CA. "Surgical Adverse Events: A Systematic Review." The American Journal of Surgery 206.2 (2013): 253-62.

12. Andrews LB, Stocking C, Krizek T, Gottlieb L, Krizek C, Vargish T, and Siegler M. "An Alternative Strategy for Studying Adverse Events in Medical Care." The Lancet 349.9048 (1997): 309-13.

13. Flin R, Mitchell L. (2009). Safer surgery: Analysing behaviour in the operating theatre. Ashgate: Aldershot

14. Calland JF, Adams RB, Benjamin DK, O'Connor MJ, Chandrasekhara V, Guerlain S, and Jones RS. "Thirty-Day Postoperative Death Rate at an Academic Medical Center." Annals of Surgery 235.5 (2002): 690-98.

15. Neale G, Woloshynowych M, and Vincent C. "Exploring the Causes of Adverse Events in NHS Hospital Practice." Journal of the Royal Society of Medicine. The Royal Society of Medicine, July 2001.

16. Bogner M. Human Error in Medicine. Hillsdale, NJ: LEA 1994.

17. Bogner M. Misadventures in Health Care. Mahwah, NJ: LEA 2004.

18. Fletcher G, Flin R, McGeorge P, Glavin R, Maran N and Patey R. "Anaesthetists' Non-Technical Skills (ANTS): Evaluation of a Behavioural Marker System." British Journal of Anaesthesia 90.5 (2003): 580-88.

19. Yule S, Flin R, Paterson-Brown S, Maran N, and Rowley D. "Development of a Rating System for Surgeons' Non-technical Skills." Medical Education 40.11 (2006): 1098-104.

20. Mitchell L, Flin R, Yule S, Mitchell J, Coutts K, and Youngson G. "Development of a Behavioural Marker System for Scrub Practitioners' Non-technical Skills (SPLINTS System)." Journal of Evaluation in Clinical Practice 19.2 (2012): 317-23.

21. Hakala T, Vironen J, Karlsson S, Pajarinen J, Hirvensalo E, and Paajanen H. "Fatal Surgical or Procedure-Related Complications: A Finnish Registry-Based Study." World Journal of Surgery 38.4 (2013): 759-64.

22. Rowlands C, Griffiths SN, Blencowe NS, Brown A, Hollowood A, Hornby ST, Richards SK, Smith $\mathrm{J}$, and Strong S. "Surgical Ward Rounds in England: A Trainee-led Multi-centre Study of Current Practice." Patient Safety in Surgery 8.1 (2014): 11. 
23. Ahmad A, Purewal TS, Sharma D, and Weston PJ. "The Impact of Twice-daily Consultant Ward Rounds on the Length of Stay in Two General Medical Wards." Clinical Medicine 11.6 (2011): 524-28.

24. Bhangu A, and Hartshorne G. "Ward Rounds: Missed Learning Opportunities in Diagnostic Changes?" The Clinical Teacher 8.1 (2011): 17-21.

25. O'Mahony S, Mazur E, Charney P, Wang Y, and Fine J. "Use of Multidisciplinary Rounds to Simultaneously Improve Quality Outcomes, Enhance Resident Education, and Shorten Length of Stay." Journal of General Internal Medicine 22.8 (2007): 1073-079.

26. Kane RL, Shamliyan TA, Mueller C, Duval S, and Wilt TJ. "The Association of Registered Nurse Staffing Levels and Patient Outcomes." Medical Care 45.12 (2007): 1195-204.

27. "The Benefits of Consultant Delivered Care." Academy of Medical Royal Colleges. 23/01/2012.

28. Pucher PH, Aggarwal R, and Darzi A. "Surgical Ward Round Quality and Impact on Variable Patient Outcomes." Annals of Surgery 259.2 (2014): 222-26.

29. Mellanby E, Hume M, Glavin R, Skinner J, Maran N. “Foundation non-technical skillsDevelopment of a behavioural marker system for newly qualified doctors in managing acutely unwell patients." Clinical Skills Managed Clinical Network 2013.

30. Hull L, Birnbach D, Arora S, Fitzpatrick M, and Sevdalis N. "Improving Surgical Ward Care." Annals of Surgery 259.5 (2014): 904-09.

31. Ingraham AM, Cohen ME, Raval MV, Ko CY, and Nathens AB. "Comparison of Hospital Performance in Emergency Versus Elective General Surgery Operations at 198 Hospitals." Journal of the American College of Surgeons 212.1 (2011): 20-28.

32. Hull Louise, Arora S, Kassab E, Kneebone R, and Sevdalis N. "Observational Teamwork Assessment for Surgery: Content Validation and Tool Refinement." Journal of the American College of Surgeons 212.2 (2011): 234-43.

33. Pucher PH, Aggarwal R, Singh P, Srisatkunam T, Twaij A, and Darzi A. "Ward Simulation to Improve Surgical Ward Round Performance." Annals of Surgery 260.2 (2014): 236-43.

34. Sevdalis N, Davis R, Koutantji M, Undre S, Darzi A, and Vincent CA. "Reliability of a Revised NOTECHS Scale for Use in Surgical Teams." The American Journal of Surgery 196.2 (2008): 184-90.

35. Walker S, Brett S, Mckay A, Lambden S, Vincent C, and Sevdalis N. "Observational Skill-based Clinical Assessment Tool for Resuscitation (OSCAR): Development and Validation."

36. Flin R, Martin L, Goeters K, Hoermann J, Amalberti R, Valot C, Nijhuis H. The development of the NOTECHS system for evaluating pilots' CRM skills. Hum Factors Aerospace Safety 2003 Resuscitation 82.7 (2011): 835-44.

37. ;3:95-117.

38. Flin RH, Crichton M, and O'Connor P. Safety at the Sharp End a Guide to Non-technical Skills. Aldershot: Ashgate, 2013.

39. Pearce CL, Conger J. Shared Leadership. London, UK: Sage, 2003. 